\title{
LOS IMAGINARIOS NEOREPUBLICANOS LIBERALES PODRAN REVOLUCIÓNAR LA DEMOCRACIA? UNA VISIÓN DESDE AMÉRICA LATINA ${ }^{1}$
}

\author{
Jorge Lora Cam ${ }^{2}$
}

\begin{abstract}
Resumen
El artículo realiza de entrada un análisis punzante del liberalismo como corriente política que ha sabido convertirse en sentido común y que ha impuesto la idea según la cual la política es ingeniería social elaborada desde las administraciones del Estado por élites intelectuales en cuyos conocimientos tienen que confiar los ciudadanos para la correcta gestión de la polis. Una visión que también ha adoptado una buena parte de la izquierda y que contrasta con una propuesta republicana que hunde sus raíces en algunas ideas clave de la filosofía clásica mediterránea; a saber: la necesidad de una participación permanente y creativa de la comunidad social que supere la atomización social, impulse una renovada práctica política y genere un nuevo ethos o cultura de vida, sin la cual todo proyecto emancipatorio pierde su razón de ser y viabilidad.
\end{abstract}

Palabras clave: Igualdad social; Imaginarios neorepublicanos; Democracia; Proyecto emancipatorio; Liberalismo

República hoy no es sustituir a un Rey por una Presidencia ni sustituir la bandera borbónica por la hermosa tricolor, por legítima que sean las emociones que despiertan en el pueblo. República es derecho, ciudadanía, derecho a tener derechos, en primer lugar los que están siendo expropiados por la acción despiadada del Gobierno. República es igualdad, distribución equitativa de la riqueza y de las cargas. República es soberanía popular, desprivatización y defensa de los asuntos y de los patrimonios públicos, empezando por el que constituye la condición misma de la vida, el patrimonio ecológico, hoy amenazado por los dueños de grandes corporaciones, amigos y consejeros de Juan Carlos Borbón.

José Errejón, Abdicación, monarquía, república, Tribuna VIENTO SUR, 11/06/2014

"en América Latina y más allá de ella, en las luchas sociales, no en las universidades, se están tejiendo ideas y pensamientos, se están construyendo entramados o, como dice el título, cosmovisiones y epistemologías otras para enfrentar la guerra capitalista y construir autonomías"

Jorge Regalado, prologo a Pensamiento crítico, cosmovisiones y epistemologías otras, para enfrentar la guerra capitalista y construir autonomía, Catedra Jorge Alonso, 2017.

\footnotetext{
${ }^{1}$ Este modesto ensayo esta dedicado a Antoni Domènech, gran repubicanista comunista, fallecido el 17 de septiembre de 2017.

${ }^{2}$ Doctor en Ciencias Políticas y en Estudios Latinoamericanos por la UNAM. Profesor investigadro del área de Estudios Latinoamericanos del Instituto de Ciencias Sociales y Humanidades. E-mail: jlcpsocio@gmail.com
} 


\section{EL CONTEXTO HISTORIZADO Y LOS CONCEPTOS}

El republicanismo ha vuelto, algunos lo esgrimen como modelo de gobierno que puede corregir las formas liberales que se han ido corrompiendo, al retroceder al despotismo o la oligarquía; o que ha sido desnaturalizado por el neoliberalismo. Otros, critican a este republicanismo liberal para recuperar el legado de las comunidades libres republicanas que habrían sustentado la concepción marxista. Estas formas de pensamiento republicano coinciden, en general, en que es necesario mas republicanismo en la vida social, en la protección de la libertad y su fundamentación en el derecho, en la ley como expresión de la voluntad popular, en la participación activa de los ciudadanos con valores cívicos y en afianzar el ejercicio de la Constitución. No obstante existen profundas diferencias.

A lo largo de la historia de América Latina el uso de la palabra república entraria en la anfibología que según la RAE "es el doble sentido, vicio de la palabra, cláusula o manera de hablar a que puede darse más de una interpretación". Una Dubia sermonis sententia, vale decir, un engaño escondido en un discurso que parece muy lejos de llevar tal cosa dentro. El examen de las perspectivas nos ayudaran a esclarecernos.

Rosler se ubica en la perspectiva analítica, cuyo interés en el estudio del lenguaje y el análisis lógico de los conceptos, se preocupan fundamentalmente por lo que los textos clásicos tienen para aportar al debate teórico, siendo partidario del contractualismo. Esta emparentado con John Rawls, quien en sus obras argumento de manera rebuscada el liberalismo político, siendo partidario del contractualismo. Un continuador fue Robert Nozick quien defendio el liberalismo de mercado, Isaiah Berlin, es otro pensador liberal centrado en la libertad. Para estos pensadores los textos son vehículos de ideas y comprobaciones diáfanas.. En este sentido muchos de ellos son eruditos como Rosler, quien intentara desarrollar teorías originales desde el concepto de república, que según el refiere "a un régimen político cuyo valor primordial es la libertad, que depende de la virtud cívica, gira alrededor del debate, sostiene el imperio de la ley, exige una actitud patriota y es fuertemente antipersonalista"3

Otro enfoque prefiere utilizar una herramienta heurística cercana a los tipos ideales weberianos, es el caso de Gabriela Rodríguez Rial que examina el "momento maquiaveliano" para el análisis de casos específicos con sus limitaciones teóricas intrínsecas a la abstracción e históricas. Trabaja instrumentos analíticos que permiten visualizar la estructura de las relaciones entre los conceptos, aunque el sentido de estos últimos sea históricamente contingente. $^{4}$

Una tercera posción, entre las mas cercanas en el debate actual, es la de los investigadores contextualistas quienes consideran que, a fin de comprender su significado de forma concertada, las obras clásicas del

\footnotetext{
${ }^{3}$ ROSLER, Andrés (2016), Razones Públicas. Seis Conceptos Básicos sobre la República, p.28Buenos Aires, Katz Editores.

${ }^{4}$ Gabriela Rodríguez Rial, La república en Hispanoamérica y sus momentos maquiavelianos: historia y actualidad político conceptual de los republicanismos. http://www.congresoalacip2017.org.
} 
pensamiento político son piezas de un debate político ubicado en un momento histórico que deben ser analizadas en el contexto de la practica política, ideologías en conflicto y convenciones lingüísticas.

Un ejemplo es Antoni Domenech quien reconoce en Marx a un gran republicanista y al que,

Primero, es necesario leerlo directamente, como un clásico, es decir, con la debida acribia filológica y con la necesaria atención a la historia contextualizada de los conceptos. Así, se evidencia que la formación básica de Marx (como jurista romanista, discípulo de Savigny, como helenista y luego como economista político, estudioso de Adam Smith y David Ricardo, entre muchos otros, y finalmente, en su compromiso político inicial, como admirador de la democracia revolucionaria de la Primera República francesa de 1793), tiene una clara ascendencia republicana, localizada en cuatro puntos fundamentales: 1) su concepción antihobbesiana de la ley y del derecho; 2) la de la libertad como un derecho constitutivo inalienable; 3) la fideicomisaria de la autoridad y del poder políticos, en tanto le impone un contenido de comisión que se encarga a alguien en caso y tiempo determinados y controlado siempre por el fideicomitente; y 4) la fiduciaria de la naturaleza de la propiedad de los medios de existencia y de producción. ${ }^{5}$

Dos errores frecuentes en el debate filosófico político Latinoamericano son, primero partir de la idea de la existencia real de repúblicas democraticas en la región y segundo considerar que la democracia equivale a liberalismo representativo. En los debates es frecuente escuchar recomendaciones del tipo: que se debe establecer la relación entre momento histórico y los conceptos republicanos, que la investigación histórica de las experiencias latinoamericanas es una tarea pendiente despues de dos siglos de republicanismo, que el neoliberalismo ha socabado al liberalismo democrático y que las lecturas historico filosóficas nos daran la orientación para corregir estas anomalías. Nunca reconocen que los subalternos en ningún tiempo tuvieron soberanía sobre las relaciones sociales, la cultura, la ley y sobre sus representantes. Y menos aun la idea de que si aceptamos que la democracia es incompatible con el capitalismo, es aun mas con el capitalismo colonial, patriarcal y racista que predomino en toda Latinoamerica, mas aun en los países de mayoría indigena. En sintesis la democracia real no existe. Lo mismo ocurre con la república. No obstante que muchos aceptan que republica y democracia fueron solo etiquetas historiográficas, conceptos flotantes, significantes vacios; analistas politicos buscan las influencias del republicanismo en instituciones que fueron formales, marginales y con confusos objetivos. Asi y todo no faltan quienes consideran que somos parte de occidente, lo que es cierto pero aceptando que en la heterogeneidad de occidente, solo fuimos y somos la parte colonial.

Creemos que el punto de partida del "cientifico social" o del demócrata radical, debería ser la busqueda de experiencias de poder democrático como capacidad de control sobre la actividad en común, en comunidad, averiguar cómo de la praxis politica de la comunidad se elaboraron y buscaron referentes escritos para repensar los legados y encontrar respuestas a su práctica. En estos momentos hay una indagación sobre respuestas exigidos por las movilizaciones democraticas que ya no confian en gestionar instituciones que resurgen en la región. Y es en períodos asi en que volvemos a analizar las experiencias, principalemente revolucionarias. Solo en ese sentido 
cobra validez la historia intelectual del republicanismo. De ser a la inversa, buscar en los hechos históricos las coincidencias con el pensamiento clásico o Europeo puede ser solo una especulación forzada y sin sentido.

Como decíamos, se contraponen dos visiones. La mirada marxista de la república es la apropiación del republicanismo desde otro ángulo de la mirada. Es una reconstrucción de la historia de la democracia plebeya, fraternal y del socialismo marxista como contenidos esenciales de la tradición republicana, que le otorgan su carácter democrático y comunista. La otra, es la liberal que busca una democracia en la que prevalezca el imperio de la ley, se limite el predominio y la influencia de grupos de interés y se establezcan las condiciones para que los ciudadanos, individual o colectivamente, tengan la posibilidad de controlar y "disputar las decisiones del gobierno". 6 Cuando se diseñan mecanismos que permiten el control institucional, que permiten resolver cuestiones de carácter público y tienen un papel esencial que cumplir en la deliberación de la sociedad. Una práctica de la ética que resulta benéfica para la sociedad. Un bien común porque genera hábitos de confianza y solidaridad. Las prácticas profesionales éticas son uno de los factores para construir sociedades a la altura de la dignidad humana. ${ }^{7}$

Este viraje del pensamiento politico liberal se da precisamente ante la mundialización del capital en las últimas tres décadas que significo la reorganización del capital y su expansión como capital financero sobre los recursos naturales y humanos, de la mano con grandes innovaciones tecnológicas, provenientes en gran medida de la industria militar en pugna por la monopolización de la violencia bajo la forma imperial y del poder político. La globalización es una geoestrategia de poder que debia administrar esa expansión, densificación y profundización del capitalismo bajo la forma de recolonización. Densificación que se expresa en la conversión de la naturaleza en mercancia, en el ingente ingreso de trabajadores al mercado, la apertura de fronteras economicas, la desregulación del mercado y apropiación de los bienes comunes, la acumulación por despojo territorial y de recursos naturales, el sometimiento de poderes nacionales y la expropiación de la escasa soberanía nacional, la gestión politica interna de los países, las reformas estructurales, la mercantilización de todos bienes y servicios, la corrupción de lo privado y lo publico. El Estado se transforma, se despoja de la soberanía, del nacionalismo anticolonial, de las politicas sociales, se posterga lo público o solo sirve para incrementar la corrupción, en el saqueo participa toda la clase política enlazada a la economía y política criminal. Paralelamente, tuvieron que eliminar resistencias, destruir la vieja socialización, empobrecer a las sociedades y darles un uso politico a la pobreza y al miedo, exterminando pueblos enteros. El neoliberalismo refiere a la gestión gubernamental, a la administración fiscal, jurídica, del expolio, de la desposesión violenta, del saqueo de los recursos, tanto de

\footnotetext{
${ }^{5}$ Antoni Domenech, Memoria, ideario y práctica de la democracia, entrevista de Julio Cesar Guanche, Temas 71, jul-sep. 2013 ${ }^{6}$ PETTIT, P. (1999), Republicanismo. Una teoría sobre la libertad y el gobierno, Barcelona: Paidós.

${ }^{7}$ Conill, J. (2003). El carácter hermenéutico y deliberativo de las éticas aplicadas, en A. Cortina y D. García-Marzá, (Eds.), Razón pública y éticas aplicadas. Los caminos de la razón práctica en una sociedad pluralista (pp. 121-141). Madrid: Tecnos.
} 
propiedad pública como particular, de las clases populares. Es delincuencia y espacios sin ley, según las propias reglas del capitalismo y recuerda lo que explica Marx que fue la acumulación originaria del capital, no frugalidad, diligencia y ahorro de los capitalistas como algunos creen, sino látigos, terrorismo, hierros candentes, la violencia partera de la historia. La desposesión y la expulsión de las masas de las comunidades campesinas de las tierras y recursos mediante los que esas comunidades habían subsistido. La política se somete al "mercado", o sea, al poder económico. Podra un liberalismo renovado cambiar esta situación?

El Liberalismo, como sabemos, es una corriente ideológica relativamente reciente, proviene como respuesta a la revolución Francesa, que surge tras la derrota de las fuerzas populares, democráticas, aunque sus raíces ideológicas son un poco anteriores, pues se encuentran en los escritos de filósofos economistas o "Fisiocracia” de la Ilustración. Domenech apunta que es un anacronismo y una falsedad señalar que John Locke o Immanuel Kant o Adam Smith eran «liberales». Y agrega, que lo que hizo luego el liberalismo decimonónico, cuyo concepto de «libertad» es básicamente el de Hobbes, fue anexarse como propia, desfigurándola, la tradición política histórica de la libertad republicana. Y luego, fabricar su propio pasado presentándolo como democrático.

El liberalismo político es la ideología orgánica de la burguesía, principalmente académica, se ha convertido en la matriz del pensamiento político contemporaneo y ultimamente, se desliza como "republicanismo". Joaquín Miras Albarrán sostiene que este pensamiento político se autorepresenta como democratico sustentado en el régimen representativo; preocupa porque ha perforado a la izquierda, aunque parten del individualismo antropológico y de la Acción Racional. El republicanismo genuino es todo lo opuesto al liberalismo, pues para este el vivir, el ethos es "vida privada" y no puede ser objeto de deliberación pública ni de política. Los liberales no consideran a la república como comunidad de vida, y ni siquiera mencionan el ethos. ${ }^{9}$ No la simple suma de individuos, sino una comunidad social que se caracteriza no solo por la ley, sino, ante todo, por poseer un modo de vida, una cultura material, buen vivir, o ethos, elaborado en común por la ciudadanía, del cual es orgánica la ley. De ahí que la política no sea una actividad restringida a los especialistas, sino que exige la participación permanente, creativa, de la totalidad de la comunidad de ciudadanos, tanto en la producción y reproducción del ethos o vivir en común, libre, como en la deliberación soberana de la ley. ${ }^{10}$

En este punto, aclarados los terminos, volvamos a America Latina y recordemos en México la multicitada carta de Mariano Otero a Mora.

Las [especulaciones políticas] que ahora se presentan son admirables por su variedad. La monarquía absoluta, la dictadura militar, las bases orgánicas, la agregación a los Estados Unidos, el comunismo, la preponderancia de la raza indígena; todos estos extravíos tienen sus apóstoles, sus escritores, sus conspiradores; mientras que el gobierno, sin plan, sin apoyo

\footnotetext{
${ }^{8}$ Philip Pettit, y en general en el pensamiento progresista, muchos inspirados en John Rawls.

${ }^{9}$ Cazarabet conversa con... Joaquín Miras Albarrán, autor de "Praxis política y Estado Republicano. Crítica del republicanismo liberal” (El Viejo Topo), http://www.cazarabet.com/conversacon/fichas/fichasl/praxispolitica.htm. P. 3

${ }^{10}$ Ibid. P. 1
} 


\section{político, sin fuerza, se reduce a conservar el statu quoy vivir de la inercia general... ${ }^{11}$}

Al comenzar el siglo XX Ricardo Flores Magón rechazaba la representación y en lo mas cercano al republicanismo auténtico, propone que las tareas delegadas a sus servidores y ministros (siervo) son las de ejecución puntual de sus acuerdos. El Soberano es el pueblo organizado activo, que delibera sobre el destino de la comunidad, crea su ethos y establece su ley. Un ejemplo de este tipo de republicanismo, es Flores Magón, que va mas allá del pensamiento, de la igualdad y los derechos, para él republica es soberanía popular, es práctica, son materialidades que se consiguen con la rebelión en busca de la libertad y felicidad. La dominación y la ausencia de libertad, de igual libertad, son puestos bajo la critica de este gran luchador. En ausencia de estas características, el uso de la denominación de Republicanismo para definir la actividad política es una falsificación.

La república para la mayoría de políticos y pensadores de esa época, no fue mas que una palabra para denominar a los nacientes estados, un fetiche que no necesitaba reflexión y si hubo debate fue escaso, intelectual y marginal. Investigadores en el campo de la historia han llegado a afirmar, como producto de los avances en el conocimiento histórico, que la tradicional línea divisoria del tiempo latinoamericano que separa colonia y república es artificiosa, por el peso de la continuidad sociopolítica posterior a la independencia, basada en la segregación y mayor opresión de los indígenas y de los pobres, el dominio de facto en la regiones, las continuidad de la violencia y guerras que legitimaron el uso de la fuerza en las disputas caudillistas, los países eran un mosaico de sociedades agrarias regionales en las que renacerían la servidumbre y la esclavitud. Los ejércitos y la Iglesia, fueron las instituciones relativamente coherentes de la sociedad del siglo XIX. Ya, al comenzar el nuevo siglo, Flores Magón, que no era un intelectual sofisticado, señala:

La Revolución francesa conquistó el derecho de pensar; pero no conquistó el derecho de vivir, y a tomar este derecho se disponen los hombres conscientes de todos los países y de todas las razas. Vivir, para el hombre, no significa vegetar. Vivir significa ser libre y ser feliz. Tenemos, pues, todos derecho a la libertad y a la felicidad. La desigualdad social murió en teoría al morir la metafísica por la rebeldía del pensamiento. Es necesario que muera en la práctica. A este fin encaminan sus esfuerzos todos los hombres libres de la Tierra.

He aquí por qué los revolucionarios no vamos en pos de una quimera. No luchamos por abstracciones, sino por materialidades. Queremos tierra para todos, para todos pan. Ya que forzosamente ha de correr sangre, que las conquistas que se obtengan beneficien a todos y no a determinada casta social. Por eso nos escuchan las multitudes; por eso nuestra voz llega hasta las masas y las sacude y las despierta, y, pobres como somos, podemos levantar un pueblo. Somos la plebe; pero no la plebe de los Faraones, mustia y doliente; ni la plebe de los Césares, abyecta y servil; ni la plebe que bate palmas al paso de Porfirio Díaz. Somos la plebe rebelde al yugo; somos la plebe de Espartaco, la plebe que con Munzer proclama la igualdad, la plebe que con Camilo Desmoulins aplasta la Bastilla, la plebe que con Hidalgo incendia Granaditas, somos la plebe que con Juárez sostiene la Reforma.

Somos la plebe que despierta en medio de la francachela de los hartos y arroja a los cuatro vientos como un trueno esta frase formidable: ¡Todos tenemos derecho a ser libres y felices!. Y el pueblo, que ya no espera que descienda a algún Sinaí la palabra de Dios grabada en unas

\footnotetext{
${ }^{11}$ Carta de Mariano Otero a Mora. Ensayo sobre el verdadero estado de la cuestion social y politica que se agita e la republica mexicana, Paginas Escogidas, Biblioteca del pensamiento legislativo y politico mexicano, Ciudad de México, 2013, p.46
} 
tablas, nos escucha. Debajo de las burdas telas se inflaman los corazones de los leales. En las negras pocilgas, donde se amontonan y pudren los que fabrican la felicidad de los de arriba, entra un rayo de esperanza. En los surcos medita el peón. En el vientre de la Tierra el minero repite la frase a sus compañeros de cadenas. Por todas partes se escucha la respiración anhelosa de los que van a rebelarse. En la obscuridad, mil manos nerviosas acarician el arma y mil pechos impacientes consideran siglos los días que faltan para que se escuche este grito de hombres: jrebeldía! ${ }^{12}$

La obra de este luchador es una reacción contra la exclusión e injusticia, contra la falsa humanidad de las clases dominantes, reivindicando el derecho de combatir tal desigualdad. Es un revolucionario republicano, que no pretende disertaciones teóricas o abstractas reflexiones sobre la evidente desigualad y la ausencia de libertad; sino que pone manos a la obra en la transformación práctica de esa realidad. Es un filósofo del pueblo, del todos somos filósofos, que impugna y contradice sin restricciones, piensa la realidad y dedica su vida a transformarla. Para Flores Magón, “el hombre es un ser libre por naturaleza, estado del que ha sido despojado por la división clasista de la sociedad y la implantación de la propiedad privada”. Se inclina por la revolución social como vía de la transformación radical, llevada a cabo por el pueblo: obreros, campesinos e indígenas, fundamentalmente. La esencia humana, se encuentra para este autor en el reino de la libertad, estado al que hay que llegar mediante la lucha. $^{13}$

Podriamos agregar a pensadores y políticos de toda Latinoamerica. Pero solo algunos, añadamos a Chile, pais desde el cual Sagredo Baeza señala que la república es

Metáfora casi perfecta del régimen instaurado en este montañoso rincón de América del Sur. Que por su normativa autoritaria hoy es difícil de identificar como republicano y que, por el temor de quienes lo sustentaban, rápidamente desaparecía al más leve movimiento social, corrientemente interpretado como amenaza. Diluyéndose su carácter democrático, transformándose en el fondo en un régimen absolutista, aunque con figura de república. ${ }^{14}$

En Perú el gran historiador del periodo republicano, Jorge Basadre, hablaba de repúblicas frustradas y el José Carlos Mariátegui de falsas repúblicas. En Perú permanecieron, en la practica, las dos republicas, la de indios y de españoles, el único frágil vínculo era el común origen de nacimiento. Cuando el Estado nacional estaba en construcción desde abajo, la globalización y el neoliberalismo se encargaron de disolver sus débiles cimientos.

Lo fundamental es que preguntándonos desde la práctica, que influencia tuvo la tradición republicana en la formación de las instituciones políticas en la primera parte del siglo XIX en América Latina, sería posible entender cómo de esa tradición surgió el liberalismo. Reiteramos la pregunta de Barrón ino sería el republicanismo sólo una etiqueta historiográfica y no una verdadera corriente histórica? ${ }^{15}$

\footnotetext{
${ }^{12}$ Ricardo Flores Magón, Vamos hacia la vida, Artículo escrito en San Francisco, California, en julio de 1907, y publicado en el mismo mes en Los Angeles, Cal., en un periódico llamado Revolución. Depués se volvió a reimprimir en el número 5 de Regeneración, del 1º de octubre de 1910. http://www.antorcha.net/biblioteca_virtual/politica/ap 1910/7.html

${ }^{13}$ Ricardo Flores Magón (1993). Antología. UNAM. Introducción y selección de Gonzalo Aguirre Beltrán. México

${ }^{14}$ Rafael Sagredo Baeza' Chile, del orden natural al autoritarismo republicano' Revista de Geografía Norte Grande, 2006, No 36, p. 5-30

15 Luis Barrón, Liberales conservadores: Republicanismo e ideas republicanas en el siglo XIX en América Latina,
} 
El mismo autor nos responde:

Un problema de la historiografía con que hasta hoy contamos es la falta de definiciones claras de lo que era, durante la primera mitad del siglo XIX, un conservador, un liberal, un centralista, un federalista, un monarquista o un republicano. El liberalismo, por ejemplo, se ha definido a veces simplemente como una ideología antimonárquica (por lo que el liberalismo se ha confundido con el republicanismo en cuanto a la proposición de una forma de gobierno). Otras se ha definido en base a sus rasgos anticlericales. Otras como un sistema de gobierno que buscaba limitar el poder. Y las más de las veces, como una ideología que se basaba en la protección de los derechos individuales. ${ }^{16}$

Esto, por supuesto, lleva a concepciones completamente diferentes de lo que debe ser el gobierno, la ley y la sociedad. Se van esbozando algunos rasgos, veamos. Para un republicano, por ejemplo, el gobierno es el encargado de asegurar que no existan relaciones de dominación entre los miembros de la sociedad, y la ley es el único medio para que el gobierno pueda interferir en la vida y los asuntos privados de los ciudadanos y asegurar que no haya relaciones de dominación. Pero el bien común, para un republicano, es más importante que el individual $\mathrm{y}$, por tanto, los derechos individuales no son tan importantes como asegurar la virtud en los ciudadanos y en los gobernantes evitar la corrupción. Para un liberal, en cambio, el fin del gobierno es asegurar la libertad individual, y la ley, cuando menos en concepto, debe intervenir lo menos posible en la vida y los asuntos privados de los ciudadanos. En el liberalismo, mientras un individuo no interfiera con los otros, la virtud no es estrictamente necesaria y buscar el provecho puramente individual no es, como lo sería para un republicano, contrario al bien común ni tampoco es una posible fuente de corrupción.

La política latinoamericana en el siglo XIX, se caracterizó por que los caudillos, los políticos, los militares, los pensadores, por lo general se ubicaban como liberales o conservadores, aunque ello no les impidió cambiar de bando de acuerdo al cambio de condiciones, ocultar sus posiciones o ignorar la constitución y las leyes con el propósito de alcanzar ventajas personales. Recordemos que la corrupción colonial, que prioriza lo privado a lo público, mantuvo sus tendencias al crecimiento con los criollos en el poder. El resultado de esta situación fue que la ilusa y prematura "sociedad republicana" constantemente fue quebrada y perturbada, en un contexto de desordenados conflictos étnicos, de clase y regionales, y la ineludible rivalidad entre los oficiales y la élite. Es un periodo colmado de diversos golpes militares, elecciones, magnicidios, anulaciones, conjuras, conspiraciones, y rebeliones. Sin embargo, ninguno de los bandos propuso cambios drásticos a la América Latina postindependentista, ni atisbos de soberanía popular ni democracia ya que compartían la naturalidad de la idea de una «soberanía aristocrática» que encarnaba una visión esencialmente jerárquica, racista y elitista de la organización social.

Estado nacional y república, como después democracia y ciudadanía, solo eran ficciones. Los conceptos no surgían de su materialidad. Los intelectuales inventan imaginarios y siempre ha sido así. Los conceptos deben

http://lasa.international.pitt.edu/lasa2001/barronluis.pdf, p. 8 
examinarse históricamente. En varios países de Latinoamérica no hubo la tan socorrida emancipación, muy pronto se recolonizó este espacio por los criollos y los ingleses, la nación no fue el fundamento del Estado y por tanto tampoco había ciudadanía ni fidelidad popular al mismo. No faltaron los rituales y simbologías de unidad frente a múltiples comunidades que no se convirtieron en nacionalidades y menos en Estado nación. De acuerdo con Hobsbawm si a fines del siglo XIX la nación se hace política en occidente, ciudadanos con soberanía colectiva, constituidos en Estado; y después de la primera guerra se fortalecen las economías nacionales, ello no ocurre en gran parte de América Latina. Si la nación hacia referencia a la unidad e independencia política, la etnicidad, la lengua común, el territorio, la memoria, la comunidad imaginada común, para algunos no paso de una fantasía.

El nuevo republicanismo en la América Latina indígena del siglo XX va mas allá pues se confronta con la permanente reedición colonialista de Norteamérica, con la exclusión y despojo de las mayorías indígenas, con las falsas republicas de las que hablaba José Carlos Mariátegui. En el siglo XXI destaca el republicanismo neoliberal de derecha y liberal de izquierda que crean nuevas quimeras.

El republicanismo en Latinoamérica tendrá una corta vida, intelectual mas que práctica, pues las condiciones obligaron a los poderosos e incipientes políticos a ajustarse a ellas para recomponer el nuevo poder, en proceso continuo de recolonización extractivista, tributario y mercantil sin afectar los cimientos oligárquicos de las estructuras sociales del período colonial. En un contexto de permanencia de las estructuras coloniales, a las luchas por el control político del nuevo Estado entre monárquicos y "republicanos", conservadores y liberales, caudillos militares y caudillos civiles y a la reiterada derrota estratégica de los sectores democráticos de la burguesía liberal, le quedan como rasgos permanentes las inestabilidades, las crisis, el pragmatismo y el triunfo de la oligarquía. En América Latina no hubo revolución burguesa, en su lugar asistimos a un proceso de reformas del Estado en función del tipo de incorporación de las oligarquías al proceso de división internacional de la producción, del trabajo y de los mercados. Reformas políticas coincidentes con la propuesta de integración extractivista semicolonial al mercado mundial frente a los conservadores centralistas que difícilmente podín defender el proteccionismo. Donde hubo una burguesía progresista-liberal latinoamericana fue derrotada -como ocurrió en Paraguay- y los sobrevivientes terminaron por fundirse con el proyecto oligárquico. Y, como en todo lo que sigue en la historia regional, los sectores burgueses mientras mas radicales, serán mas violentamente reprimidos y perseguidos.

Al margen del debate entre conservadores y liberales, un orden conservador en lo político y liberalprogresista en lo económico es la característica de la dominación oligárquica. Los regímenes liberales y su razón instrumental se encuentra fundada en los beneficios de la explotación interna, de sus vínculos mercantiles y bancarios mas que del capitalismo como modo de producir. Las oligarquías, externamente serán meros agentes de

\footnotetext{
${ }^{16}$ Ídem. P. 6
} 
los intereses de los capitales ingleses o norteamericanos, internamente ejercerán todo el poder tiránica y despóticamente contra indígenas, negros y clases subalternas.

No podríamos entender estas disputas ideológicas sin su correlato con el desarrollo capitalista y la construcción del Estado nacional. Recordemos que el fundamento económico de la nación es el desarrollo del intercambio sobre la base de la economía capitalista y este no existió en la región sino incipientemente desde mediados del siglo XIX. En Perú mas que en Bolivia se frustró con la guerra del Pacífico 1879-1883 que estanco al país por cuatro décadas por lo menos. Otras guerras destruyeron al Paraguay y a otros países. El capitalismo colonial es un fenómeno del siglo XX, en particular de la segunda mitad. La existencia de relaciones económicas determinadas, la comunidad de territorio, de idioma y de cultura constituyen los rasgos característicos de la nación. Se puede afirmar, por consiguiente, que la nación, en el verdadero sentido de la palabra, es un producto directo de la sociedad capitalista, si esta es colonial no es posible lograr más que naciones en germen. Los países que no han logrado un desarrollo capitalista no pueden ser considerados, propiamente, como naciones, mas aun si la mayoría de la población es excluida de la ciudadanía y mas bien es victima del colonialismo en movimiento y la colonialidad del poder vista como estructura de poder.

Por último, un caso más, Argentina, autoreconocida por muchos como parte de Europa o el país mas cercano a ella. Allí, como en el resto de esta periferia el Estado estuvo tan subordinado a Inglaterra y luego a Estados Unidos como los demás y también el Estado creó en gran parte a la oligarquía. El Estado en el establecimiento de las condiciones capitalistas de producción implica que, en la periferia, no es posible hacer abstracción de la nación ni presuponer la generalización del fetichismo de la mercancía. En Latinoamérica, es preciso considerar el Estado a partir del sistema capitalista mundial y en marcos donde la generalización de la mercancía no se establece en el todo social. Sergio Zeta opina que:

La democracia liberal nunca se asemejó a una real democracia ya que rechaza el poder soberano del pueblo y lo reemplaza por un "Estado de derecho" en el que el ciudadano no debe hacer nada (ni se le permite hacerlo ya que "el pueblo no gobierna ni delibera") sino hacer uso de "libertades" individuales, eventualmente y sin afectar el "derecho" del otro. Una historia latinoamericana de golpes militares durante gran parte del siglo XX llevó a valorar la importancia de estos derechos constitucionales, pero al costo de confundirlos con una real democracia. ${ }^{17}$

La burguesía tiende a constituirse en estado nacional porque es la forma que mejor responde a sus intereses y que garantiza un mayor desarrollo del capitalismo. De acuerdo con Hobsbawm.

Pertenece exclusivamente a un período concreto y reciente desde el punto de vista histórico. Es una entidad social sólo en la medida en que se refiere a cierta clase de estado territorial moderno, el «estado-nación», y de nada sirve hablar de nación y de nacionalidad excepto en la medida en que ambas se refieren a él. Por otra parte, al igual que Gellner, yo recalcaría el elemento de artefacto, invención e ingeniería social que interviene en la construcción de

\footnotetext{
${ }_{17}$ Sergio Zeta, Elecciones primarias y algunos debates estratégicos urgentes para una izquierda sin brújula, Herramienta, http://www.herramienta.com.ar/content/ Bs. As.
} 


\section{naciones. ${ }^{18}$}

Siguiendo a este gran historiador las nacionalidades y los estados construyeron las naciones. En algunos países de Latinoamérica los movimientos de emancipación nacional expresan esta tendencia, pero por su propia naturaleza no lograron consolidar Estados nacionales. En algunos Estados, particularmente los de mayoría indígena, con plurinacionalidades, el poder está ejercido por lumpenburguesías, grandes terratenientes y caciques locales, el proceso de nacionalización adquiere una amplitud y una virulencia particulares, confronta las nociónes de raza y genero, adscritos a la idea de colonialidad del poder, y se expresa en una violencia que no representa más que un aspecto de la lucha general contra las supervivencias esclavistas y serviles y por la democracia. La historia nos demuestra, en efecto, que la lucha nacional ha coincidido siempre con la lucha contra la servidumbre. Otra distinción respecto a la vieja metrópoli radica es que en Latinoamérica ya no será solo la masacre el modo de proceder habitual del gobernar.

Desde la Revolución francesa pareciera que se necesitaran otras mas para avanzar en la construcción de la república, en Latinoamérica hubo una segunda revolución en México, dos mas en Bolivia, otra mas en Nicaragua, triunfos electorales, movimientos guerrilleros y si bien hubo avances democráticos no estuvieron acompañados de proyectos republicanos. ${ }^{19}$

Distinto fue en la república de Cuba, que ha construido un sistema muy particular y único en América Latina. El cubano Fernández Estrada considera que en Cuba,

Al defender el republicanismo hoy lo hacemos no solo de una forma de gobierno, sino de una cultura de igualdad, inclusión, participación, deliberación, no discriminación, legalidad, transparencia, responsabilidad social, solidaridad, soberanía popular, propiedad comunal, disfrute de las cosas comunes, compromiso con el futuro de la humanidad, aceptación de la diferencia, y con la intolerancia solo para los intolerantes, porque estos quieren ofender la ley del pueblo. ${ }^{20}$

El republicanismo, ante la fuerza del poder del capital sobre la política, se convierte, una vez más, en un horizonte de expectativa para quienes, en contra de la opinión general y a contracorriente de las lógicas de dominación, apuestan por la centralidad de un nuevo debate colectivo, ajustado a unas políticas claras, orientado hacia la búsqueda del bien común y afirmando, como corolario de lo anterior, la preeminencia de la política democrática y participativa sobre las lógicas inevitables del capitalismo financiarizado y la crisis del liberalismo representativo.

Hace mas de cuarenta años, Umberto Cerroni, de los pocos marxistas que debatió con Norberto Bobbio, señalaba que "la democracia política se mantiene y se desarrolla sólo luchando contra el capitalismo y, por

\footnotetext{
${ }^{18}$ Eric Hobsbawm, Naciones y nacionalismo desde1780, Ed. Crítica, Grijalbo-Mondadori, Barcelona, 1991

${ }^{19}$ Con Macpherson diríamos que estos países siguieron descansando en una sociedad de mercado posesiva y en esa dimensión nunca pudieron evadirse del éthos individualista posesivo.

${ }^{20}$ Julio Antonio Fernández Estrada, "La República está pendiente porque está pendiente la soberanía del pueblo, en todas partes, también en Cuba”. Entrevista18/05/2017.
} 
ello, la expansión de la democracia política es un aspecto específico de la lucha contra el capitalismo y por la construcción de las formas políticas de un socialismo evolucionado"21

En contraposición, los gobiernos llamados progresistas de siglo XXI no modificaron al capitalismo, tampoco la forma liberal de gobierno, nunca revirtieron las contrarreformas neoliberales y persistieron en mantener las estructuras extractivistas. Al mantener las concreciones del neoliberalismo - privatizaciones, política económica, despojo territorial, deuda, derechos laborales y sociales, etc,- continuaron con las mismas políticas que favorecieron al capital trasnacional, financiero, junto a la lumpenburguesía nativa y a la nueva burguesía. Al privilegiarse la permanencia en el poder y/o la reelección a rajatabla, se privilegia la estabilidad política y abandona el impulso a la lucha de clases por la democracia y el socialismo en aras de la representación.

El extractivismo es mas que una estructura económica, pues afecta a los pueblos, indígenas o no, empobrece las regiones y afecta a la construcción de una nueva economía. Son políticas que traen consigo la corrupción y la ausencia de nuevas formas de acción política socialista y comunitaria, mas bien se impulso la política neoliberal representativa que mantenía casi incólumes los viejos poderes mas aun cuando se asociaron a ellos para mantener la estabilidad económica.

Se apoyo a regímenes de derecha del continente, es el caso de Brasil que en aras de la defensa de la economía nacional, del crecimiento y la mantención de la necesaria estabilidad con fines electorales, se permitió el corruptor apoyo de sus trasnacionales a regímenes de ultraderecha como a Santos, Bachelet, Calderón, Peña Nieto, y en el insólito caso peruano fue transquinquenal Fujimori-Toledo-Alan-Humala-PPK,

Los avances logrados en ciertas coyunturas - con Chávez o los primeros años de Evo- fueron revertidos por las nuevas burguesías en el poder y no hubo mas avances socialistas. En Bolivia la constitución creo al Estado Plurinacional de Bolivia que no paso de ser una forma liberal de Estado. Los defensores del progresismo parten del respeto al sistema, a la globalización, el neoliberalismo y el sometimiento a la amenaza geopolítica imperial, como si las revoluciones no pudiesen cambiar las relaciones de los Estados con el entorno y construyendo algo nuevo desde abajo.

En Venezuela la Constituyente creo la Asamblea Nacional de la República Bolivariana de Venezuela, órgano unicameral que ejerce el poder legislativo en dicho país y el poder ciudadano como innovaciones al régimen liberal. Su ambigüedad y conciliación lo condujeron al empoderamiento de una oposición golpista que usa principalmente el sabotaje económico y el llamado a la insurrección conduciendo al país a un callejón cuya salida parece no ser el cambio de constitución. La critica de Lander al proceso gubernamental y al papel de una izquierda burocrática y en una buena parte burguesa, queda realmente corta. No se colocó en debate el

\footnotetext{
${ }^{21}$ Umberto Cerroni, “¿Existe una ciencia política marxista?”, artículo publicado en Rinascita número 46, de 21 de noviembre de 1975- Taula de Canvi, Barcelona, número 1 y 2.
} 
eurocentrismo, el racismo, ni la mala critica al falso republicanismo liberal ni el desarrollo colonial y la llamada colonialidad. El capitalismo colonial no ha intentado cambiarse. Allí no hubo ninguna desconexión, desoccidentalización o política anti mercado, lo que hay es una lucha de clases compleja,

De este modo llegamos a la ideología republicana moderna y contemporánea, que sigue intrínsecamente ligada a una idea de nación y pierde fuerza en los Estados ante la globalización neoliberal. Mientras que, por lo mismo, gana espacios en sectores populares.

Ángel Duarte ubica al republicanismo en su historicidad y señala que se ajusta a los combates políticos contra las lógicas de exclusión que implementa el liberalismo doctrinario. Dirá:

Frente al concepto de sufragio como función social, para el que, en consecuencia, había que estar preparado — cualificación académica, avecindamiento, posesiones, sentido de moderación—, el republicanismo, todo él hasta 1874, contempla el voto como un derecho inalienable mediante el cual la población adulta, y masculina hasta 1932, participa en la elección de representantes parlamentarios y en la expresión del criterio soberano del pueblo y la nación de ciudadanos. El republicanismo cuaja, también, en los procesos de contestación a los efectos sociales distorsionadores inherentes al tránsito a la economía capitalista sostenida sobre el concepto burgués de propiedad. ${ }^{22}$

\section{NEOREPUBLICANISMO LIBERAL Y REPUBLICANISMO COMUNISTA}

El debate histórico sobre republicanismo, creemos que solo se justifica si buscamos las experiencias prácticas asociadas al aprendizaje en los combates por la democracia. La controversia sobre republicanismo reitera de alguna manera la disputa acerca de la democracia, que en sus extremos comunistas y liberales se confrontan, habiendo muchas posiciones intermedias. Si en el capitalismo avanzado existen complejidades en estos esfuerzos, en América Latina quedo contaminada por una oscura y vieja contienda entre liberalismo y conservadurismo. Únicamente, partiendo de la práctica, de la historia y la claridad conceptual, podremos esclarecernos. El republicanismo liberal cobra nuevos bríos ante la crisis del liberalismo y de su ideología de la representación considerada fundamento de la democracia.

Roberto Gargarella intentará precisar las diferencias que separan a republicanos liberales de los liberales. Le queda claro que ambas tradiciones no son compatibles y que en Latinoamérica se impuso el liberalismo. Establece,

Que el republicanismo liberal en contraposición con una visión orgánica de la sociedad, la sociedad es vista como un todo cuyas partes deben convivir armónicamente e integradas entre sí, intenta disolver cualquier distinción drástica entre el ámbito de lo público y lo privado. Otorga importancia a una ciudadanía activa, comprometida con la salud política del Estado. Mientras que el liberalismo, enfatiza en la distinción entre las

\footnotetext{
22 Àngel Duarte Montserrat, El pasado (republicano) que vuelve, el futuro posible, Mientras Tanto, 2012, http://www.mientrastanto.org/boletin-109/notas/el-pasado-republicano-que-vuelve-el-futuro-posible
} 
esferas de lo público y lo privado; los individuos preexisten a cualquier organización social, y son más substanciales que los colectivos. La vida personal merecen ser protegida contra cualquier imposición en nombre de los demás incluyendo la preferencias gubernamentales. El estado siendo neutro no puede interferir con la moral privada de los individuos.

Otra diferencia es que las políticas orientadas a maximizar el bienestar general, para el bien común han de reconocer un limite infranqueable en los derechos individuales, amenazados por la tiranía de las mayorías. Le preocupa sostener un conjunto de derechos individuales inviolables, y a partir de allí, también, es que concibe a la libertad límite de la política democrática.

Para el republicanismo liberal, es lo inverso, los derechos deben encontrar su limite en las políticas del bien común. Se apoya en la voluntad mayoritaria. La principal amenaza, provendría de minorías opresoras. Concibe a la libertad no como libertad frente a las mayorías, sino como consecuencia del autogobierno de la comunidad: soy libre en la medida en que soy miembro de una comunidad que controla su propio destino, y participante en las decisiones que gobiernan sus asuntos. Este ideal del autogobierno será resistido por la política liberal. El republicanismo liberal subordina la organización política y económica de la sociedad a la obtención de buenos ciudadanos, mientras que el liberalismo comienza preguntándose de qué modo el gobierno debería tratar a sus ciudadanos, destacando el principio de justicia idóneo para tratar a las personas de modo considerando intereses y fines distintos. El republicano mas radical comienza preguntándose de qué modo es que los ciudadanos pueden alcanzar el autogobierno, y busca las formas políticas y las condiciones sociales que promuevan su ejercicio significativo." ${ }^{23}$

Entre los posmarxistas destaca el republicanismo institucional que propone incorporar el movimiento social a las instituciones y desde allí posibilitar una nueva subjetividad cultural y cambio político, lo que implica una visión de neutralidad estatal capaz de ver por el interés general respetando la ley. De este modo se acercan al republicacionismo cívico de Pettit y Arendt que también implica un elemento participativo democratizante y en casos un cambio de políticas gubernamentales. Lo que es cierto es que la institucionalización de los movimientos se ha venido dando en Europa y en algunos regímenes progresistas de Latinoamérica sin resultados significativos. Mas bien, como es sabido, las institucionalizaciones acaban con los movimientos. Al parecer, sus detractores creen que falta una garantía social que solo podría estar dada por un sujeto social autónomo y la construcción de otra cultura, otra sociedad y otra economía. Surge la pregunta, de que nos sirve el debate republicanista, acotado por la ideología neoliberal, frente a las estructuras de poder económico financieras y político institucionales?

Con la ayuda de Octavio Majul, a grandes rasgos podemos resumir el republicanismo institucional -a

\footnotetext{
${ }^{23}$ Roberto Gargarella, EL REPUBLICANISMO Y LA FILOSOFÍA POLÍTICACONTEMPORÁNEA, en Teoría y Filosofía Política, la tradición clásica y las nuevas fronteras. Atilio Boron, Sala de Lectura - Biblioteca Virtual del Consejo Latinoamericano de Ciencias Sociales, CLACSO
} 
pesar de que el no lo llama institucional- desde la articulación de los conceptos de libertad, interés público y Estado con sus instituciones. Este republicanismo acepta la intromisión en la libertad individual, en el sujeto de libertad, y acepta que solo hay ausencia de dominación si un Estado interviene, la garantiza y la posibilita.: la máxima expresión de la libertad no es el individuo solitario, sino aquel que forma parte de un Estado que se la garantice. $^{24}$

Majul, sin embargo, considera que para este republicanismo el Estado puede ser la principal amenaza de dominación de los individuos e introduce los conceptos de interés público y bien común. El interés de todos, cobra así preponderancia. En correspondencia, el enemigo principal del republicanismo es el interés privado participando del poder político. No obstante que estas ideas son muy europeas, deben aceptar que donde prime el interés particular no puede haber republicanismo. Majul observa que en la tensión entre el interés privado y el interés público se encuentra la explicación de las más grandes vicisitudes del republicanismo. Si el Estado es el garante de la libertad no lo es independientemente de la participación de la ciudadania activa. La contradicción radica en que el liberalismo cree que con una ingeniería institucional adecuada el sistema político funciona, mientras que el republicano cree que sola, la institucionalidad, tampoco basta. Ambas posiciones no han progresado. Mas aun si en los tiempos que vivimos crece el uso privado de las instituciones públicas y la concentración del poder político, abriendo la posibilidad del uso arbitrario del poder y, por ende, la utilización del poder público para favorecer el interés privado, lo que define la corrupción. La solución la encuentran en multiplicar las instancias de control del poder político ya sea con organizaciones de la sociedad civil o con la división de poderes. Al mismo tiempo hace del conjunto de las leyes y su respeto, la garantía de la libertad, el poder sea dividido y controlado, donde la ciudadanía participe principalmente mediante el control del poder político. En realidad, la relación entre ciudadano y Estado es fragil y este último cada vez menos garantiza la libertad; este republicanismo se disuelve en el neoliberalismo, que por su propia naturaleza deja de lado al espacio de lo común.

Para Steve Pincus, el liberalismo no es antagónico del republicanismo, si el gobierno expresa la voluntad y promueve el interés de lo común como un todo, lo publico, con una ciudadanía activa relacionada con la libertad y una sociedad agraria no capitalista, en donde la virtud cívica, amenazada por la corrupción, fuera la base del poder político. Esta ideología, que armoniza esos elementos es el liberalismo, ideas republicanas con la promoción de la sociedad comercial. ${ }^{25}$

Continua Majul mostrándonos otra vertiente del republicanismo que ofrece una solución diferente al problema del interés privado en la política. Amplía el concepto de poder para examinar el peligro de la intromisión del interés particular en la política, centrado no tanto en poder político como en el poder extra político, principal

\footnotetext{
${ }^{24}$ Octavio Majul Conte, ¿Qué es el Republicanismo?, http://www.revistaatandocabos.com.ar/que-es-republicanismo-octaviomajul-conte/, marzo 2017.

${ }^{25}$ La primera revolución moderna: Pincus, Steve; 2013 Acantilado.
} 
amenaza al interés común. Individuos y grupos de la sociedad civil o global, que poseen tal poder para determinar el asunto de todos. Un Estado que no haga frente a los grupos de interés no es un Estado republicano, y por ende, sus ciudadanos no son libres. La amenaza de la influencia del poder privado debe ser resuelta por el poder político, en la medida que la amenaza a la república son grupos que poseen poder, este republicanismo necesita de un Estado poderoso que impida su intromisión. De alli que sea negado por otros republicanos al permitir el autoritarismo político o, alimentar el populismo. En sintesis, el hombre se hace libre y tiene al Estado como la cristalización institucional. ${ }^{26}$

Es una verdadera quimera liberal sostener que el verdadero hombre republicano es aquel que se compromete con el problema público, fomenta la participación e interviene. Y otra ilusión es colocar a las elecciones como la principal fuente de control democrático y que por ello se le llame republicanismo democrático. En Latinoamerica y otras regiones la democracia entendida como el ejercicio del voto, se ha vuelto ineficiente para el servicio de la política. Ejercer control sobre el poder político y que el gobierno acate los deseos de la ciudadanía, no es mas que un liberalismo iluso que desconfía de la concentración de poder y por ello busca multiplicarlo difusa e institucionalmente para responder a una enorme cantidad de demandas producto de la multiculturalidad. Alli encuentran los politólogos sus tareas intelectuales e incluso laborales: como lograr la real división del poder político, la alternancia en el gobierno, la proliferación de propuestas políticas, las candidaturas independientes, la prolongación o reducción del ejercicio del poder, la creación de organismos de control del poder económico, etc.

Y con ello estamos ante otro problema de mas fondo y es que el liberalismo económico traiciona al liberalismo político. El neoliberalismo, enfatiza el aspecto económico y renuncia a la construcción política del liberalismo clásico, es una concepción empresarial y eficientista de la política para satisfacer las crecientes y diversas demandas, aquí la política es un sistema, un servicio, que satisface peticiones.

El nuevo liberalismo, que discurre por debajo de un neoliberalismo marcado por la desposesión, el expolio y la violencia, es una construcción ideológica burguesa que se opone a un cambio radical, que sin embargo por postular la representación aparece como democrático. El republicanismo liberal es antidemocrático, para ellos la sociedad es el conjunto de individualidades pre constituidas por la razón innata, pretende un gobierno formado por representantes, pues desecha a las masas y no acepta un poder de los pobres, que serían los sujetos de una verdadera democracia. Hablar de democracia burguesa es un oxímoron y en una América Latina en recolonización una perversión pues es imposible hablar de ella cuando la mayoría es despojada y excluida. El liberalismo en su nacimiento es antidemocrático e incluso antiparlamentario, y con mayor razón, antirrepublicano.

O como dice Julio Cesar Guanche resumiendo las ideas de Antoni Domënech ... la tradición liberal sería una tradición reciente, decimonónica, surgida como reacción a la

\footnotetext{
${ }^{26}$ Ibíd. P.2
} 
Revolución francesa. Tiende a una visión de la ley, de ascendencia hobbesiano-utilitarista, como algo opuesto a los derechos. Tiene, además, una concepción de la «libertad» poco amiga de su inalienabilidad, así como una noción no fideicomisaria de la autoridad política. $\mathrm{Y}$, en cuarto lugar, tiende a ver los derechos de propiedad como derechos de propiedad y apropiación exclusiva y excluyente, no como dimanantes de un fideicomiso. ${ }^{27}$

Pero los poderosos dominan o están imbricados con las estructuras económico-financieras y políticoinstitucionales, aun con la convencional separación de poderes. Por tanto, en esa posición subyace una idea unilateral: la infravaloración de la capacidad oligárquica del control político-institucional y, por tanto, la necesidad de la democratización del Estado y el reequilibrio de poder entre las fuerzas sociales y políticas. El conflicto estrictamente sociopolítico quedaría en un segundo plano, al igual que la construcción de sujetos sociales y fuerzas políticas que condicionan y conforman nuevas capacidades e instituciones. Al no priorizar el proceso relacional e histórico no superaría el reduccionismo determinista.

Se trata de la versión más conservadora del liberalismo. Los liberales igualitarios como Rawls ${ }^{28} \mathrm{o}$ Dworkin $^{29}$ son una opción mas cercana a las ideas ofrecidas por el republicanismo. Ambos liberales buscan un núcleo común de la tradición democrática. Rawls, intenta ofrecer una alternativa al utilitarismo, que dominó la tradición anglosajona del pensamiento político desde el siglo XIX. Parte de la idea de justicia con equidad, o sea, que los derechos y libertades fundamentales de los ciudadanos sean pensados para personas libres e iguales. Suscribe el modelo deliberativo de la democracia, que implica la participación y articulación de la gente en los distintos ámbitos, la creación de foros públicos de debate ciudadano para resolver los conflictos centrales que se presentan en su comunidad. Para Dworkin, considerado antipositivista, los problemas substanciales estan referidos a los principios morales y no a los hechos jurídicos ni a las estrategias de interpretación. Las cuestiones mas abstractas, se acreditan por su papel en la solución de problemas particulares. Ambos coinciden en que los ciudadanos tomen el control sobre los destinos de su comunidad en el ideal del autogobierno desde una critica radical y la de formulación de reformas a las instituciones básicas haciéndolas, mas igualitarias valorando la igualdad cívica. Se oponen al financiamiento electoral y a la corrupción, rechazan el pluralismo "democrático" de grupos de interés. En el sentido de estos pensadores considerados clásicos, lo más avanzado, aunque insuficiente, es el llamado 'republicanismo cívico' de Philip Pettit o Hannah Arent, para quienes se deben completar sus propuestas con el cambio de políticas y modelos de sociedad, que busquen la armonía de las estructuras del poder institucional.

En oposición a este liberalismo idealista republicano, pensamos que la República es importante por que no es cosa del pasado, menos de especulaciones filosóficas, tampoco es patrimonio liberal. Por el contrario, es la forma de política popular, del bien público y que por ella hubieron grandes combates e incluso revoluciones, en

\footnotetext{
${ }^{27}$ Antoni Domenech, Memoria, ideario y práctica de la democracia, entrevista de Julio Cesar Guanche, Temas 71, jul-sep. 2013

${ }^{28} 8$ Rawls, J. (1973): A Theory of Justice, Oxford University Press, Oxford.
} 
particular desde que se preconiza la igualdad, la libertad y la solidaridad. Como asunto del pueblo, las ideas republicanistas -lo mismo que las democráticas- son parte del presente, muchos defienden el socialismo democrático que va mas alla del representacionismo liberal, como resultado, de una conjunción entre democracia y república. Como señala Boaventura de Souza Santos revolucionar la democracia y democratizar la revolución. Precisariamos que lo prioritario es lo segundo, mas aun los paises colonizados.

Como veremos existen intentos de contraponer ambas concepciones. Acaso se puede dividir el poder político y el poder extra político? Un primer acercamiento conceptual nos ayudara en encontrar una respuesta.

Para Joaquín Miras Albarrán "una república es una sociedad cuyo vivir en común es asunto público, deliberado, elaborado voluntariamente en común por parte de todos sus ciudadanos" ${ }^{\prime 30} \mathrm{Si}$ la cultura material de vida esta regida por todos es obvio que se opone a la representación. La soberanía estará en manos del pueblo y no de elites aristocratizantes, en minorías selectas, donde la soberanía es poseída y ejercida por el congreso y el gobierno. Surge de la praxis de los pobres, de sus comunidades y sus luchas y por ello coloca a la comunidad en prioridad ontológica frente al individuo al crear la cultura material, el ethos ${ }^{31}$ y la eticidad, ejerce dominio en comunidad y ejercita el poder en todos los ámbitos con capacidad de control de la actividad. La movilización democrática inspira el nuevo pensamiento político enlazado a tradiciones intelectuales de la libertad que solo puede darse entre iguales.

Miras Albarrán se da a la tarea de la reelaboración plebeya de la tradición republicana, a partir de la Revolución Francesa que da lugar a la primera república democrática de la Contemporaneidad. Donde se prepara y forja el pensamiento democrático, revolucionario, libertador, contemporáneo. Reconstruye la tradición republicana con la concepción de "política como actividad ejercida por la totalidad de la ciudadanía, el pueblo o demos, para dirigir desde la sociedad civil, el destino de la propia comunidad, dentro de la cual se desarrolla y alcanza su perfección el individuo". Desde alli define la República como una comunidad social que posee un modo de vida, una cultura material, una forma de vivir, una libertad republicana, como no dominación, no supeditación del individuo ciudadano a ninguna voluntad individual ajena, todo ello elaborado en común por la ciudadanía. Es mas que una simple suma de individuos, que se caracteriza solo por una ley, asi sea orgánica. No podemos prescindir de un análisis del momento histórico que vive el capitalismo en el que todos coexistimos, una condicion indispensable si no queremos incidir directamente en el riesgo del idealismo teorico o especulativo, o sea, de desacoplamiento crónico en relacion a las dinámicas reales de producción de la vida y transformación del mundo.

\footnotetext{
${ }^{29}$ Ronald Dworkin, Los derechos en serio, editorial: ariel, 1984

${ }^{30}$ Joaquín Miras Albarrán, entrevista por Salvador López Arnal, Rebelión, 27/02/2017.

${ }^{31}$ RAE "Conjunto de rasgos y modos de comportamiento que conforman el carácter o la identidad de una persona o una comunidad".
} 
Desde esta perspectiva la política no puede ser una actividad restringida a los especialistas, mas bien exige la constitución del demos, la participación organizada, permanente, creativa, de la totalidad de la comunidad de ciudadanos, tanto en la producción y reproducción del ethos o vivir en común, libre, como en la deliberación soberana de la ley. Las tareas encargadas por el pueblo soberano y activo, deliberante de su destino, que asi crea su ethos y legisla su ley, a sus servidores son las de ejecución puntual de sus acuerdos. No existe República o es una falsificación, si el pueblo no es protagosnista, si no se acaba con el poder politico como ambito externo a la sociedad, si faltan estos rasgos, si no hay democratización de la propiedad y liquidación del dominio de los ricos, si no hay un proyecto económico al servicio de la liberación y, si la libertad no es un fin.

De acuerdo con Antonio Antón, se abren nuevos procesos cívicos con una nueva perspectiva. Se ubica en la encrucijada europea actual, frente a la dinámica de la crisis del representacionismo liberal y de involución social, democrática e institucional en un espacio más disgregado y débil, bajo la hegemonía del bloque de poder liberal-conservador y del capital financero con las trasnacionales en la politica.

Compara el republicanismo con el comunitarismo, y señala que en su versión liberal se abstenía de dar algunos pasos "anti-liberales" que el comunitarismo sí los da. Tampoco los liberales otorgan una relevancia moral especial a las prácticas tradicionales de la comunidad, con su vigorosa concepción moral. Para Antón, una defensa genuina y coherente del ideal del autogobierno, que el republicanismo pretende asumir, puede requerirle un compromiso muy fuerte con ciertos derechos "liberales" tradicionales.

El republicanismo, para evitar caer en una mera normativa procedimental, que vaya mas allá del sufragio, con sus creativos mecanismos de elusión, se debe completar de una democracia social y económica avanzada, sobre una base igualitaria y la conformación de un sujeto transformador autónomo. Se trata de superar la concepción jurídica de la igualdad y de la democracia y no quedarse solo en republicanizar la democracia, sino en consolidar las garantías transformadoras socioeconómicas y político-culturales ante los bloqueos del poder oligárquico. ${ }^{32}$

En estos tiempos de neoliberalismo, ha ocurrido mas bien, en lugares como México una contrarevolución repúblicana de derecha, desapareciendo lo publico y los principales derechos sociales, donde los individuos, las agrupaciones, la ciudadanía, quedaron expuestos a la violencia, el desempleo, el saqueo de los público, la injusticia, la arbitrariedad, la impunidad, el secreto de Estado, la perdida de derechos y libertades, la censura y otras cuestiones sensibles como las multiples criminales formas de convivencia y supervivencia. La ley, la justicia están pendientes y por lo tanto está suspendida la República.

Fernández Liria, quien se considera un comunista, propone algo similar, un republicanismo

\footnotetext{
${ }^{32}$ Antón, A. Democracia social hoy. Un nuevo ciclo sociopolítico por la democracia y la igualdad, Editorial Académica Española, 2016
} 
'institucional', en una interpretación algo restrictiva de la democracia o la democratización, como participación popular en las instituciones e imperio de la ley. Pero ese concepto va más allá de la expresión de la simple incorporación de las fuerzas transformadoras a las instituciones políticas. Además, democracia (republicanizar) es fundamentalmente igualdad jurídica y de derechos civiles y políticos y, en el mejor de los casos, posibilidad de acceso al poder gubernamental de las fuerzas del cambio, regulación de la plurinacionalidad y construcción europea más participativa.

La organización republicana de la sociedad, implica para esta izquierda populista cambios estructurales de envergadura, exige llevar a cabo una política económica, cultural y social fundamentada en los derechos, deberes e intereses de la ciudadanía, recuperar prácticamente los valores fundacionales de Libertad, Igualdad y Fraternidad, el acceso a la cultura, mediante educación pública gratuita, laica, obligatoria, democrática y científica, el derecho a una sanidad pública de calidad, la superación de toda forma de discriminación, el acceso a la gestión de los medios de comunicación, de acuerdo a la diversidad y complejidad de culturas e identidades existentes.

Como hemos podido observar, Joaquín Miras, es mas radical y critico de todos los republicanismos que hemos visto, Realiza de entrada un análisis punzante del liberalismo como corriente política que ha sabido convertirse en sentido común y que ha impuesto la idea según la cual la política es ingeniería social elaborada desde las administraciones del Estado por élites intelectuales en cuyos conocimientos tienen que confiar los ciudadanos para la correcta gestión de la polis. Una visión que también ha adoptado una buena parte de la izquierda y que Miras propone contrastar mediante una propuesta republicana que hunde sus raíces en algunas ideas clave de la filosofía clásica mediterránea; a saber: la necesidad de una participación permanente y creativa de la comunidad social que supere la atomización social, impulse una renovada práctica política y genere un nuevo ethos o cultura de vida, sin la cual todo proyecto emancipatorio pierde su razón de ser y viabilidad.

Seguimos en la modernidad y de ella habrá que recoger los elementos emancipatorios, desde otros lugares, desde las alteridades negadas (indígenas, negros, mujeres, lgtb, desempleados, etc) por esa modernidad, tomar las experiencias de rebeldía, las luchas emancipatorias, las instituciones, el Estado de derecho, la economía, la crítica. Luchar desde la calle y en la red, en el campo y la ciudad, desde las potencialidades, en todos los terrenos de concreción de las prácticas de relación social en el siglo XXI.

\title{
CAN THE LIBERAL NEOREPUBLICAN IMAGINARIES REVOLVE DEMOCRACY? A VISION FROM LATIN AMERICA
}

\begin{abstract}
The article begins with a sharp analysis of liberalism as a political current that has become common sense and has imposed the idea according to which the policy is social engineering developed from the state administrations by intellectual elites whose knowledge they have to trust the citizens for the correct management of the polis. A vision that has also adopted a good part of the left and that contrasts with a republican proposal that has its roots in some
\end{abstract}


key ideas of classical Mediterranean philosophy; namely: the need for a permanent and creative participation of the social community that overcomes social atomization, promotes a renewed political practice and generates a new ethos or culture of life, without which every emancipatory project loses its raison d'etre and viability.

Keywords: Social equality; Neorepublican imaginaries; Democracy; Emancipatory project; Liberalism.

\section{REFERENCIAS}

BAEZA, Rafael Sagredo: Chile, del orden natural al autoritarismo republicano: Revista de Geografia Norte Grande, 2006, No 36, p. 5-30.

BARRÓN, Luis. Liberales conservadores: Republicanismo e ideas republicanas en el siglo XIX en América Latina, http://lasa.international.pitt.edu/lasa2001/barronluis.pdf, p. 8.

CONILL, J. (2003). El carácter hermenéutico y deliberativo de las éticas aplicadas, en A. Cortina y D. GarcíaMarzá, (Eds.), Razón pública y éticas aplicadas. Los caminos de la razón práctica en una sociedad pluralista (pp. 121-141). Madrid: Tecnos.

CONTE, Octavio Majul. ¿Qué es el Republicanismo?, http://www.revistaatandocabos.com.ar/que-esrepublicanismo-octavio-majul-conte/, marzo 2017.

CERRONI, Umberto. “¿Existe una ciencia política marxista?", artículo publicado en Rinascita número 46, de 21 de noviembre de 1975- Taula de Canvi, Barcelona, número 1 y 2.

DOMENECH, Antoni. Memoria, ideario y práctica de la democracia, entrevista de Julio Cesar Guanche, Temas 71, jul-sep. 2013

DWORKIN, Ronald. Los derechos en serio, editorial: ariel, 1984.

GARGARELLA, Roberto. EL REPUBLICANISMO Y LA FILOSOFÍA POLÍTICACONTEMPORÁNEA, en Teoría y Filosofía Política, la tradición clásica y las nuevas fronteras. Atilio Boron, Sala de Lectura - Biblioteca Virtual del Consejo Latinoamericano de Ciencias Sociales, CLACSO.

HOBSBAWM, Eric. Naciones y nacionalismo desde 1780, Ed. Crítica, Grijalbo-Mondadori, Barcelona, 1991.

MAGÓN, Ricardo Flores. (1993). Antología. UNAM. Introducción y selección de Gonzalo Aguirre Beltrán. México.

MONTSERRAT, Àngel Duarte. El pasado (republicano) que vuelve, el futuro posible, Mientras Tanto, 2012, http://www.mientrastanto.org/boletin-109/notas/el-pasado-republicano-que-vuelve-el-futuro-posible.

PETTIT, P. (1999), Republicanismo. Una teoría sobre la libertad y el gobierno, Barcelona: Paidós.

RAWLS, J. (1973): A Theory of Justice, Oxford University Press, Oxford. 
RIAL, Gabriela Rodríguez. La república en Hispanoamérica y sus momentos maquiavelianos: historia y actualidad político conceptual de los republicanismos. http://www.congresoalacip2017.org.

ROSLER, Andrés (2016), Razones Públicas. Seis Conceptos Básicos sobre la República, p.28. Buenos Aires, Katz Editores.

ZETA, Sergio. Elecciones primarias y algunos debates estratégicos urgentes para una izquierda sin brújula, Herramienta, http://www.herramienta.com.ar/content/.

Trabalho enviado em 12 de dezembro de 2017. Aceito em 01 de janeiro de 2018. 